\title{
Axial compressive strength of human vertebrae trabecular bones classified as normal, osteopenic and osteoporotic by quantitative ultrasonometry of calcaneus
}

\author{
Reinaldo Cesar ${ }^{1 *}$, Tomaz Puga Leivas ${ }^{2}$, Cesar Augusto Martins Pereira ${ }^{2}$, Ricardo Simionato Boffa ${ }^{3}$, \\ Roberto Guarniero ${ }^{2,4}$, Rodrigo Bezerra de Menezes Reiff ${ }^{5}$, Antônio Mandeli Netto ${ }^{1}$, \\ Carlos Alberto Fortulan ${ }^{1}$, João Manuel Domingos de Almeida Rollo ${ }^{6}$ \\ ${ }^{1}$ Department of Mechanical Engineering, São Carlos School of Engineering, University of São Paulo, São Carlos, SP, Brazil. \\ ${ }^{2}$ Institute of Orthopedics and Traumatology, General Hospital, Faculty of Medicine, University of São Paulo, São Carlos, SP, \\ Brazil. \\ ${ }^{3}$ Interunits Bioengineering Post-graduate Program, University of São Paulo, São Carlos, SP, Brazil. \\ ${ }^{4}$ National Institute of Science and Technology in Biofabrication, São Paulo, SP, Brazil. \\ ${ }^{5}$ Departament of Medicine, Federal University of São Carlos, São Carlos, SP, Brazil. \\ ${ }^{6}$ Departament of Materials Engineering, São Carlos School of Engineering, University of São Paulo, São Carlos, SP, Brazil.
}

Abstract Introduction: Biomechanical assessment of trabecular bone microarchitecture contributes to the evaluation of fractures risk associated with osteoporosis and plays a crucial role in planning preventive strategies. One of the most widely clinical technics used for osteoporosis diagnosis by health professionals is bone dual-energy X-ray absorptiometry (DEXA). However, doubts about its accuracy motivate the introduction of congruent technical analysis such as calcaneal ultrasonometry (Quantitative Ultrasonometry - QUS). Methods: Correlations between Bone Quality Index (BQI), determined by calcaneal ultrasonometry of thirty (30) individuals classified as normal, osteopenic and osteoporotic, and elastic modulus (E) and ultimate compressive strength (UCS) from axial compression tests of ninety (90) proof bodies from human vertebrae trabecular bone, which were extracted from cadavers in the twelfth thoracic region $\left(\mathrm{T}_{12}\right)$, first and fourth lumbar $\left(\mathrm{L}_{1}\right.$ and $\left.\mathrm{L}_{4}\right)$. Results: Analysis of variance (ANOVA) showed significant differences for E $(\mathrm{p}=0.001)$, for UCS $(\mathrm{p}=0.0001)$ and BQI. Spearman's rank correlation coefficient (rho) between BQI and E $(r=0.499)$ and BQI and UCS $(r=0.508)$ were moderate. Discussion: Calcaneal ultrasonometry technique allowed a moderate estimate of bone mechanical strength and fracture risk associated with osteoporosis in human vertebrae.

Keywords Osteoporosis, Calcaneal ultrasonometry, Trabecular bone, Human vertebra, Axial compression test, Correlation.

\section{Introduction}

Osteoporosis is defined as a metabolic bone disorder and skeletal disease characterized by low bone mass and microarchitectural deterioration. It generally occurs in women, at the menopause age (usually over 50 ) attributed

This is an Open Access article distributed under the terms of the Creative Commons Attribution License, which permits unrestricted use, distribution, and reproduction in any medium, provided the original work is properly cited.

How to cite this article: Cesar R, Leivas TP, Pereira CAM, Boffa RS, Guarniero R, Reiff RBM, Mandeli A No, Fortulan CA, Rollo JMDA. Axial compressive strength of human vertebrae trabecular bones classified as normal, osteopenic and osteoporotic by quantitative ultrasonometry of calcaneus. Res Biomed Eng. 2017; 33(2):91-96. DOI: $10.1590 / 2446-4740.04116$

*Corresponding author: Department of Mechanical Engineering, São Carlos School of Engineering, University of São Paulo - USP, Av. Trabalhador São-Carlense, 400, Parque Arnold Schimidt, CEP 13566-590, São Carlos, SP, Brazil. E-mail: rcesar@sc.usp.br Received: 25 August 2016 / Accepted: 16 April 2017 to declining levels of estrogen and in men (usually over age 70) by testosterone or estradiol deficiency (Ebeling, 2008; Society..., 2014). Osteoporosis is characterized by a progressive loss of bone mass, increased porosity, deterioration of microarchitecture, cracks, degradation of collagen fibers and unbalance in reabsorption and bone formation rates. Specifically in trabeculae there is a reduction of number, thickness and connectivity and shape deterioration from plate to rod format (National..., 2014; Parfitt et al., 1987). These factors, combined or isolated, causes lower resistance which entails higher fracture risk with little or without trauma, mainly in trabecular bone from regions of femoral neck and vertebrae (Hernlund et al., 2013), increasing morbidity and mortality (Kanis et al., 2013).

Trabecular bone, from Latin trabeculae which means "small beam", is considered a composite, viscoelastic, heterogeneous and anisotropic material (Cauley et al., 2010; Doblaré et al., 2004). It presents a complex structure 
with irregular organization, which is dependent on the applied mechanical stress (Cesar et al., 2013).

Bone mineral density (BMD) (measured in $\mathrm{g} / \mathrm{cm}^{2}$ ) evaluated by dual-energy X-ray absorptiometry (DEXA) is the main clinical method (gold standard) for predicting morphometric vertebral fracture in postmenopausal women, however it cannot predict osteoporosis accurately because it evaluates density as the only relevant parameter (Adams, 2013; Watts et al., 2005).

Quantitative ultrasound (QUS) of calcaneal bone is considered a low-cost technique and a fast exam with absence of ionizing radiation. This technique allows clinical assessment of bone quality from the elastic properties, which vary as function of bone loss (Raum et al., 2014). The most commonly used parameters are the speed of sound (SOS), broadband ultrasound attenuation (BUA) and bone quality index or "stiffness index" (BQI) (Guglielmi and Terlizzi, 2009). BQI is a measure that is not necessarily related to the mechanical strength of bone calculated from normalized values of SOS and $\mathrm{BUA}, \mathrm{BQI}=(0.67 \times \mathrm{BUA}+0.28 \times \mathrm{SOS})-420$, based on the average young adults (Liu et al., 2012) and usually expressed as "T-scores" in the same manner as those obtained by DEXA (Shenoy et al., 2014) and classified as normal ( $>-1)$, osteopenic (between -1 and -2.5 ) and osteoporotic $(<-2.5)$ (National..., 2014).

Axial compression tests allow the analysis of the biomechanical behavior of cylindrical or cubic proof bodies of trabecular bone (dry or wet) with standardized dimensions. Axial compression is the most common type of biomechanical loading in the human body due to gravity and allows the characterization of bone quality by the analysis of the elastic modulus (E) and ultimate compressive strength (UCS) associated with osteoporosis (Roux et al., 2010).

The hypothesis of this study is the existence of correlations and significant differences between trabecular bone analyzed by different characterization techniques, among which: BQI values, QUS and mechanical properties. Hence, 30 Brazilian individuals (human cadavers) were classified as normal (considered healthy), osteopenic and osteoporotic by QUS from the calcaneus of which also was performed $\mathrm{BQI}$ values, followed respective extraction of 90 proof bodies of vertebral regions T12, L1 and L4 for axial compression to obtain E and UCS.

\section{Methods}

Vertebral segments of human cadavers were extracted from the thoracic region $10\left(\mathrm{~T}_{10}\right)$ to 5 lumbar $\left(\mathrm{L}_{5}\right)$, according to the procedures approved by the Research Protocol n ${ }^{\circ} 408 / 11$ of the Research Ethics Committee of the Medical School of the University of São Paulo (CEP-USP) and regulations established by the Capital Deaths Checking Service (SVOC) of the University of São Paulo. The vertebrae of the regions $\mathrm{T}_{12}$ and $\mathrm{L}_{1}$ were chosen because they have a higher rate of fractures and the $\mathrm{L}_{4}$ has a better distribution of trabeculae and axial alignment to the cranial-caudal axis in the vertebral body (Suzuki, 2009). The minimum number of samples $(\mathrm{N}=8.64)$ was determined as a function of the quantitative variables for an infinite population (Fontelles et al., 2010) and is defined by Equation 1.

$N=\left(\frac{Z_{\alpha / 2} S D}{S E}\right)^{2} \rightarrow N=8.6$

were, $\mathrm{Z}_{\alpha / 2}$ : critical value for the desired degree of confidence (usually: 1.96 (95\%); SD: standard deviation of the average; and SE: standard error of the average $(\mathrm{SD}=1.80 \mathrm{MPa}, \mathrm{SE}=1.2 \mathrm{MPa}$, according to Rodrigues (2004). The adopted sample size was ten $(\mathrm{N}=10)$ for each group: normal, osteopenic and osteoporotic, totalizing thirty (30) subjects.

Cadavers were selected with known cause of death, 12 hours after death interval, over 21 years of age and excluded if diagnosed with infectious diseases, trauma history, deformities, cancer, injuries, deformations, excessive feet fatty tissue layers or signs of surgeries on the thoracic-lumbar region.

Calcaneus QUS measurements were performed by the Aquilles Insight ultrasonometry equipment (GE MEDICAL SYSTEMS LUNAR ${ }^{\circledR}$ ) three (03) times on the left and right foot each, taking the general average between them.

Extraction of vertebral segments was made with the cadavers in the dorsal decubitus position and the vertebrae interest location (from T10 to L5) was set apart by inserting a surgical needle in the adjacent intervertebral discs. Appropriate surgical tools were used for dissection and separation of the vertebrae from the discs and immediately stored in a commercial chest freezer at $-20^{\circ} \mathrm{C}$. Samples were extracted using a trephine drill, with an internal diameter of $10 \mathrm{~mm}$ and at low speed (bench drilling machine) (Figure 1a) in order to avoid excessive heat, crushing or shearing of trabeculae during trephine penetration in the axial direction. The upper and lower surfaces of the cylindrical samples were cut with a diamond disk orthogonally to obtain parallelism and achieve the specimen standardized dimensions of $20 \mathrm{~mm}$ of height (Figure 1b). Most of bone marrow was removed (Figure 1c) by physiological saline application (sodium chloride $0.9 \%$ ) and stored in an amber vial (for protection against light degradation) in freezing temperature $\left(4^{\circ} \mathrm{C}\right)$.

The obtained specimens $(20 \times 10 \mathrm{~mm})$ were immersed in saline solution and kept at room temperature $\left(21^{\circ} \mathrm{C}\right)$ for 1 hour before the analysis in a Universal Testing Machine equipped with a $981 \mathrm{~N}$ load cell (KRATOS, model K5002, Cotia-Brasil), shown in Figure 2.

The tests were performed at the Biomechanics Laboratory (LIM 41)/Institute of Orthopedics and Traumatology (IOT-HCFMUSP), São Paulo, Brazil. Due to the inexistence of a specific rule in the American Society 
a)

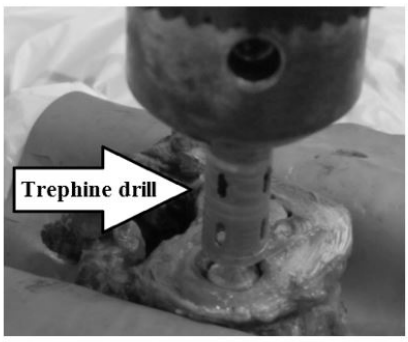

b)

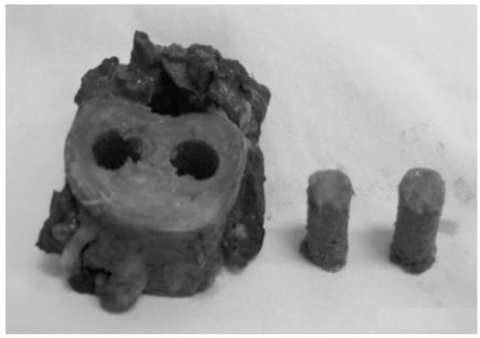

c)

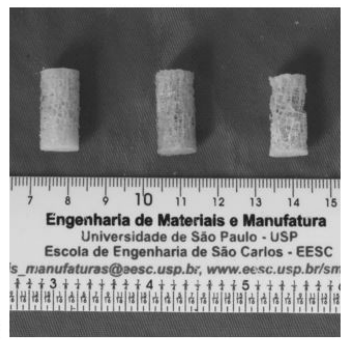

Figure 1. (a) Vertebral body trephine drill penetration; (b) Cylindrical specimens of trabecular bone; (c) Specimens (20x10) mm without bone marrow of $\mathrm{L}_{1}$ region, classified as normal, osteopenic and osteoporotic.

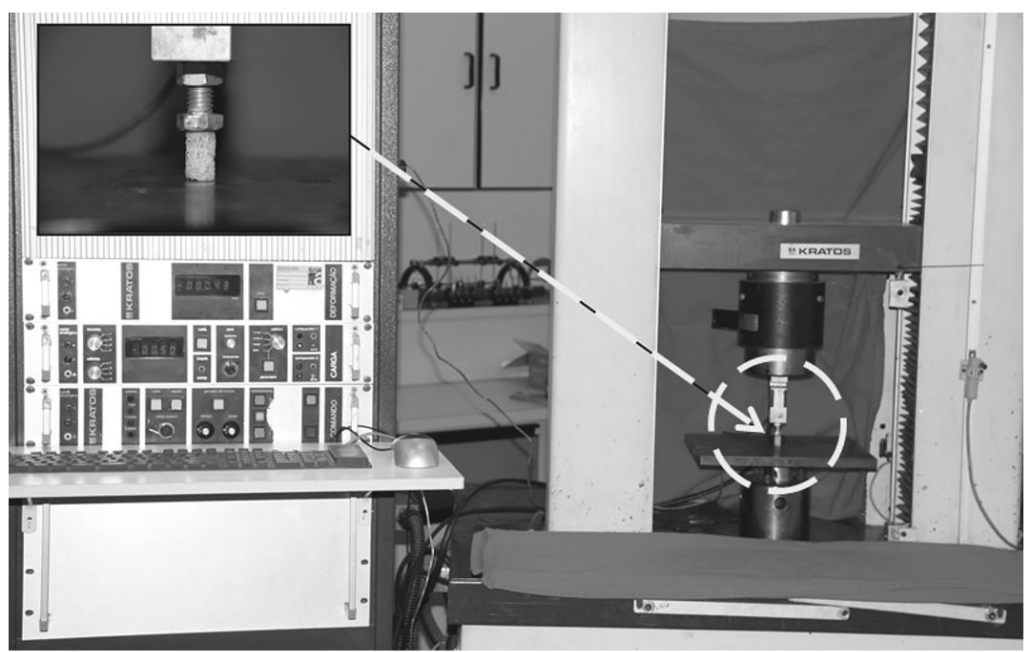

Figure 2. Proof body (in detail) under axial compression by Universal Testing Machine.

for Testing and Materials (2016) for compression tests on trabecular bone, compression was performed at the lowest rate $(5 \mathrm{~mm} / \mathrm{min})$ to minimize experimental errors.

Levene and Brown-Forsythe tests for Homogeneity of Variances (HOV) assumption showed no significance $(\mathrm{p}>0.05)$ and then ANOVA analysis of variance (5\% significance level) was performed to compare the mechanical parameters E, UCS and BQI, according to the classification done by calcaneus ultrasonometry (normal, osteopenic and osteoporotic). When the difference was significant, Tukey Kramer HSD multiple comparison test was used. Spearman's rank correlation coefficient (denoted by $\rho$ or rho) was calculated for analysis of independent non-parametric parameters. A linear correspondence was adopted when the correlation coefficient (r) was equal or greater than the critical value (rc) (Fontelles et al., 2010), given by Equation 2 .

$\mathrm{N}=4+\left(\frac{\mathrm{Z}_{\alpha / 2}+\mathrm{Z}_{\beta}}{0.5 \ln \left(\frac{1+\mathrm{rc}}{1+\mathrm{rc}}\right)}\right)^{2} \rightarrow \mathrm{rc}=0.499 \cong 0.5$

were, $\mathrm{N}$ : number of samples $(\mathrm{N}=30) ; \mathrm{Z}_{\alpha / 2}$ : critical value for the desired degree of confidence (1.96
$(95 \%))$; and $Z_{\beta}$ : critical value for adopted degree of confidence $(0.84(20 \%))$. The Pearson correlation (r) expresses quantitatively the relationship between two variables and is classified as follows: $r=1$ (perfect correlation); $\mathrm{r}=0.8 \rightarrow 1$ (very high correlation); $\mathrm{r}=0.6 \rightarrow 0.8$ (high correlation) and $\mathrm{r}=0.4 \rightarrow 0.6$ (moderate correlation). Therefore, all correlation values equal or above $\mathrm{rc}=0.499$ were accepted and otherwise rejected.

\section{Results}

The results of descriptive statistics (mean - M, standard deviation - SD, minimum value - Min, maximum value-Max), ANOVA analysis, multiple comparisons by Tukey Kramer HSD of the bone quality index (BQI) of 30 individuals and mechanical properties (E) and (UCS) of 90 proof bodies of trabecular bone proportionally distributed by regions $\mathrm{T}_{12}, \mathrm{~L}_{1}$ and $\mathrm{L}_{4}$ of 30 vertebral segments (30 human cadavers), are presented in the Tables 1,2. Table 3 shows the values of the respective Spearman's correlations coefficients of the parameters Age, BQI, E and UCS. 
Table 1. Descriptive statistics of Age, BQI, E and UCS of trabecular bone between the regions $\mathrm{T}_{12}, \mathrm{~L}_{1}$ and $\mathrm{L}_{4}$ of 30 human vertebral segments, determined by mechanical testing of axial compression and classified as normal, osteopenic and osteoporotic bone by the QUS.

\begin{tabular}{|c|c|c|c|}
\hline \multirow[t]{2}{*}{ Parameter } & \multicolumn{3}{|c|}{$\begin{array}{c}\text { Groups } \\
\mathbf{M} \pm \text { SD } \\
(\text { Min - Max) }\end{array}$} \\
\hline & Normal & Osteopenic & Osteoporotic \\
\hline Age (Year) & $\begin{array}{c}65.000 \pm 15.549 \\
(47.000-87.000)\end{array}$ & $\begin{array}{c}77.500 \pm 9.301 \\
(62.00-93.000)\end{array}$ & $\begin{array}{c}82.500 \pm 10.277 \\
(68.000-95.000)\end{array}$ \\
\hline BQI & $\begin{array}{c}107.167 \pm 18.764 \\
(77.000-133.000)\end{array}$ & $\begin{array}{c}72.017 \pm 6.518 \\
(60.333-80.333)\end{array}$ & $\begin{array}{c}53.950 \pm 5.364 \\
(41.833-60.500)\end{array}$ \\
\hline $\mathrm{E}(\mathrm{MPa})$ & $\begin{array}{c}134.693 \pm 50.999 \\
(52.089-196.301)\end{array}$ & $\begin{array}{c}85.475 \pm 32.397 \\
(45.946-134.882)\end{array}$ & $\begin{array}{c}65.119 \pm 23.905 \\
(38.618-105.825)\end{array}$ \\
\hline UCS (MPa) & $\begin{array}{c}2.270 \pm 1.142 \\
(0.711-4.789) \\
\end{array}$ & $\begin{array}{c}1.239 \pm 0.476 \\
(0.617-1.889)\end{array}$ & $\begin{array}{c}0.944 \pm 0.396 \\
(0.477-1.536)\end{array}$ \\
\hline
\end{tabular}

Table 2. Analysis of comparisons of Age, BQI, E and UCS by ANOVA test and multiple comparisons by Tukey Kramer HSD.

\begin{tabular}{|c|c|c|c|c|}
\hline \multirow[t]{2}{*}{ Parameter } & \multirow{2}{*}{$\frac{\text { ANOVA }}{\text { p }}$} & \multicolumn{3}{|c|}{$\begin{array}{c}\text { Multiple comparations by } \\
\text { Tukey Kramer HSD }\end{array}$} \\
\hline & & \multicolumn{2}{|c|}{ Groups } & \multirow{2}{*}{$\begin{array}{c}\mathbf{p} \\
0.069\end{array}$} \\
\hline \multirow{3}{*}{ Age (Year) } & \multirow{3}{*}{$0.009 *$} & Normal & Osteopenic & \\
\hline & & Normal & Osteoporotic & $0.008 *$ \\
\hline & & Osteopenic & Osteoporotic & 0.626 \\
\hline \multirow{3}{*}{ BQI } & \multirow{3}{*}{$0.0001 *$} & Normal & Osteopenic & $0.0001 *$ \\
\hline & & Normal & Osteoporotic & $0.0001 *$ \\
\hline & & Osteopenic & Osteoporotic & $0.006 *$ \\
\hline \multirow{3}{*}{$\mathrm{E}(\mathrm{MPa})$} & \multirow{3}{*}{$0.001 *$} & Normal & Osteopenic & $0.018 *$ \\
\hline & & Normal & Osteoporotic & $0.010 *$ \\
\hline & & Osteopenic & Osteoporotic & 0.456 \\
\hline \multirow{3}{*}{ UCS (MPa) } & \multirow{3}{*}{$0.001 *$} & Normal & Osteopenic & $0.013 *$ \\
\hline & & Normal & Osteoporotic & $0.001 *$ \\
\hline & & Osteopenic & Osteoporotic & 0.657 \\
\hline
\end{tabular}

$*=$ Significant difference. Significant for $\mathrm{p}=0.01$ to 0.05 ; Very significant $\mathrm{p}=0.001$ to 0.01 ; Extremely significant for $\mathrm{p}<0.001$.

Table 3. Correlation of BQI, E and UCS by Spearman test.

\begin{tabular}{ccc}
\hline \multicolumn{2}{c}{ Variables } & r \\
\hline BQI & Age (Year) & -0.501 \\
BQI & E (MPa) & 0.499 \\
BQI & UCS (MPa) & 0.508 \\
E (MPa) & Age (Year) & -0.584 \\
UCS (MPa) & Age (Year) & -0.684 \\
\hline
\end{tabular}

\section{Discussion}

Mean values (Table 1) of Age of individuals (human cadavers) on the vertebral segments $\left(\mathrm{T}_{12}, \mathrm{~L}_{1}\right.$ and $\left.\mathrm{L}_{4}\right)$ were smaller in the normal group, intermediate in osteopenic and higher in osteoporotic, while BQI, E and UCS were higher in the normal group, intermediate in osteopenic and lower in osteoporotic. Mean values of E showed a reduction of $51.654 \%$ of the osteoporotic group compared to the normal and UCS a reduction of $58.414 \%$.

ANOVA (Table 2) showed significant differences in the parameters Age, E and UCS, extremely significant for BQI. Multiple comparisons by Tukey Kramer HSD showed significant differences in the $\mathrm{E}$ (Normal/Osteopenic and Normal/Osteoporotic $)(p=0.018$ and $p=0.010)$ and UCS (Normal/Osteopenic), very significant differences in the Age (Normal/Osteoporotic), BQI (Osteopenic/Osteoporotic) and UCS (Normal/Osteoporotic) and extremely significant differences in the BQI (Normal/Osteopenic and Normal/Osteoporotic). However, ANOVA analysis showed the same significant difference between those groups. Multiple comparisons procedures by Tukey-Kramer (HSD) set out UCS as the most significant difference between normal and osteoporotic groups. This result can be justified due to 
the higher mineral density and trabecular bone strength of calcaneus in healthy subjects. One hypothesis for the lesser significant differences between osteopenics and osteoporotics groups with respect to E and UCS is the inaccuracy of QUS in defining the transition point.

BQI parameters (Table 3) showed moderate inversely proportional correlations with Age and directly proportional correlations with $\mathrm{E}$ and UCS. The elastic modulus (E) also presented moderate inversely proportional correlations with Age, even superior to those of BQI, yet there was no significant correlations with UCS, which in turn was highly inversely correlated with Age.

These results indicate that the complementary use of calcaneal ultrasonometry technique in the therapeutic evaluation of mechanical strength (trabecular bone quality) and fracture risk of human vertebrae is associated with osteoporosis. However useful, it is not a substitute method to the bone densitometry (DEXA) of human vertebrae, which is the gold standard clinical reference, but a relevant additional clinical examination.

The hypothesis was confirmed, moderate Spearman's rank correlation coefficients were identified between the results of bone quality index ("stiffness index" - BQI) determined by calcaneal ultrasonometry and the age of the individuals, elastic modulus (E) and the ultimate compressive strength (UCS) evaluated by axial compression tests of human vertebrae (cadavers).

\section{Acknowledgements}

This research was supported by Coordination for the Improvement of Higher Level Personnel (CAPES), National Council for Scientific and Technological Development (CNPq) (protocol n. 149100/2010-8) and São Paulo Research Foundation (FAPESP) (protocol n. 2010/51698-0). The authors would like to thank the Institute of Orthopedics and Traumatology of the Clinical Hospital of University of São Paulo - School of Medicine, member of the National Science and Technological Institute for Biofabrication - INCT BIOFABRIS, the School of Engineering of São Carlos for the partnership, GE MEDICAL SYSTEMS LUNAR $^{\circledR}$ by loan of the Aquilles Insight ultrasonometry equipment and to all people involved in the collection and testing of samples.

\section{References}

Adams JE. Advances in bone imaging for osteoporosis. Nature Reviews. Endocrinology. 2013; 9(1):28-42. PMid:23232496. http://dx.doi.org/10.1038/nrendo.2012.217.

American Society for Testing and Materials-ASTM International. West Conshohocken: ASTM [cited 2016 Jan. 1]. Available from: https://www.astm.org
Cauley JA, Blackwell T, Zmuda JM, Fullman RL, Ensrud KE, Stone KL, Barrett-Connor E, Orwoll ES. Correlates of trabecular and cortical volumetric bone mineral density at the femoral neck and lumbar spine: the osteoporotic fractures in men study (MrOS). Journal of Bone and Mineral Research. 2010; 25(9):19-58. PMid:20572023. http://dx.doi.org/10.1002/ jbmr.86.

Cesar R, Boffa RS, Fachine LT, Leivas TP, Silva AMH, Pereira CAM, Reiff RBM, Rollo JMDA. Evaluation of trabecular microarchitecture of normal osteoporotic and osteopenic human vertebrae. Procedia Engineering. 2013; 59:6-15. http://dx.doi. org/10.1016/j.proeng.2013.05.087.

Doblaré M, Garcia JM, Gomez MJ. Modeling bone tissue fracture and healing: a review. Engineering Fracture Mechanics. 2004; 71(13-14):1809-40. http://dx.doi.org/10.1016/j. engfracmech.2003.08.003.

Ebeling PR. Osteoporosis in men. The New England Journal of Medicine. 2008; 358(14):1474-82. PMid:18385499. http:// dx.doi.org/10.1056/NEJMcp0707217.

Fontelles MJ, Simões MG, Almeida JC, Fontelles RGS. Metodologia da pesquisa: diretrizes para o cálculo do tamanho da amostra. Revista Paraense de Medicina. 2010; 24:57-64.

Guglielmi G, Terlizzi F. Quantitative ultrasound in the assessment of osteoporosis. European Journal of Radiology. 2009; 71(3):425-31. PMid:19651483. http://dx.doi.org/10.1016/j. ejrad.2008.04.060.

Hernlund E, Svedbom A, Ivergård M, Compston J, Cooper C, Stenmark J, Kanis JA. Osteoporosis in the European Union: medical management, epidemiology and economic burden. Archives of Osteoporosis. 2013; 8(1-2):136. PMid:24113837. http://dx.doi.org/10.1007/s11657-013-0136-1.

Kanis JA, McCloskey EV, Johansson H, Cooper C, Rizzoli R, Reginster JY. European guidance for the diagnosis and management of osteoporosis in postmenopausal women. Osteoporosis International. 2013; 24(1):23-57. PMid:23079689. http://dx.doi.org/10.1007/s00198-012-2074-y.

Liu JM, Ma LY, Bi YF, Xu Y, Zhao HY, Sun LH, Tao B, Li XY, Wang WQ, Ning G. A population-based study examining calcaneus quantitative ultrasound and its optimal cut-points to discriminate osteoporotic fractures among 9352 Chinese women and men. The Journal of Clinical Endocrinology and Metabolism. 2012; 97(3):800-9. PMid:22170722. http://dx.doi. org/10.1210/jc.2011-1654.

National Osteoporosis Foundation - NOF. Clinician's Guide to Prevention and Treatment of Osteoporosis [Internet]. Washington: NOF; 2014 [cited 2016 Jan. 1]. Available from: http://nof.org/files/nof/public/content/file/2791/upload/919.pdf

Parfitt AM, Drezner MK, Glorieux FH, Kanis JA, Malluche H, Meunier PJ, Ott SM, Recker RR. Bone histomorphometry: Standardization of nomenclature, symbols, and units. Journal of Bone and Mineral Research. 1987; 2(6):595-610. PMid:3455637. http://dx.doi.org/10.1002/jbmr.5650020617.

Raum K, Grimal Q, Varga P, Barkmann R, Glüer CC, Laugier P. Ultrasound to assess bone quality. Current Osteoporosis Reports. 2014; 12(2):154-62. PMid:24652476. http://dx.doi. org/10.1007/s11914-014-0205-4.

Rodrigues MES. Análise do risco de fratura óssea por ultrasonometria e ensaio mecânico de compressão [dissertation]. 
São Carlos: University of São Paulo; 2004. http://dx.doi. org/10.11606/D.82.2004.tde-22042004-093459.

Roux JP, Wegrzy J, Arlot ME, Guyen O, Delmas PD, Chapurlat R, Bouxsein ML. Contribution of trabecular and cortical components to biomechanical behavior of human vertebrae: an ex vivo study. Journal of Bone and Mineral Research. 2010; 25(2):356-61. PMid:19653808. http://dx.doi.org/10.1359/jbmr.090803.

Shenoy S, Chawla JK, Sandhu JS. Multisite quantitative ultrasound: it's comparison with dual energy X-ray absorptiometry in the diagnosis of osteoporosis. Journal of Orthopaedics and Allied Sciences. 2014; 2(2):40-4.
Society of Obstetricians and Gynaecologists of Canada SOGC. Osteoporosis in menopause. Journal of Obstetrics and Gynaecology Canada. 2014: 36(9 eSuppl C):S1-15.

Suzuki N. The acute osteoporotic vertebral compression fracture [thesis]. Göteborg: University of Gothenburg; 2009.

Watts NB, Geusens P, Barton IP, Felsenberg D. Relationship between changes in $\mathrm{BMD}$ and nonvertebral fracture incidence associated with risedronate: reduction in risk of nonvertebral fracture is not related to change in BMD. Journal of Bone and Mineral Research. 2005; 20(12):2097-104. PMid:16294263. http://dx.doi.org/10.1359/JBMR.050814. 